Revista de Derecho

Universidad Católica del Norte

Sección: Estudios

Año 18 - No 2, 2011

pp. $189-216$

\title{
LOS OBISPOS DE LA PROVINCIA ECLESIÁSTICA DE ECUADOR Y LA CODIFICACIÓN DEL DERECHO CANÓNICO DE 1917: LOS “POSTULATA EPISCOPORUM" ACERCA DE LOS BIENES ESPIRITUALES Y TEMPORALES ${ }^{*}$
}

\section{Carlos Salinas ARaneda ${ }^{* *}$}

RESUMEN: La redacción del primer Código de Derecho Canónico que tuvo la Iglesia latina fue ordenada por el papa san Pío X en 1904. La tarea codificadora, empero, no fue obra de un grupo cerrado de expertos, sino que tuvo en cuenta el parecer del episcopado latino, el que fue consultado en dos momentos diferentes; en ambos fueron consultados los obispos de Ecuador. En este trabajo se estudia, a partir de la documentación guardada en el Archivo Secreto Vaticano, el aporte de los obispos ecuatorianos en el primero de dichos momentos, cuando los obispos fueron consultados acerca de las principales modificaciones y correcciones que debían hacerse al derecho canónico en vigor, en particular, sus sugerencias acerca de los bienes espirituales y temporales de la Iglesia.

Palabras CLAVE: Código de Derecho Canónico de 1917 - obispos ecuatorianos - postulata episcoporum - bienes espirituales - bienes temporales.

\section{BISHOPS CHURCH OF THE PROVINCE OF ECUADOR AND THE CODIFICATION OF CANON LAW OF 1917: THE "POSTULATA EPISCOPORUM" ABOUT THE SPIRITUAL AND TEMPORAL GOODS}

ABSTRACT: The wording of the first Code of Canon Law which the Latin Church had was ordained by Pope St. Pius X in 1904. The coding task, however, was not the work of a closed group of experts, it

* Este trabajo forma parte de la investigación Fondecyt 1095074 de la que el autor es investigador responsable.

Fecha de recepción: 1 de marzo de 2011.

Fecha de aceptación: 9 de agosto de 2011.

** El autor es doctor en derecho por la Universidad Complutense de Madrid y doctor en derecho canónico por la Universidad Pontificia Santo Tomás in Urbe (Angelicum) de Roma. Es profesor titular de Historia del Derecho y de Derecho Canónico en la Facultad de Derecho de la Pontificia Universidad Católica de Valparaíso. Correo electrónico: csalinas@ucv.cl 
took into account the views of Latin Bishops, which was asked at two different times, both were asked the bishops of Ecuador. In this paper it is studied, from the documents stored in the Vatican Secret Archives, the contribution of the Ecuadorian bishops during the first time when the bishops were asked about major changes and corrections to be made in the canon law force, in particular, their suggestions about the spiritual and temporal goods of the Church.

KEY WORDS: Code of Canon Law 1917 - ecuadorian bishops postulata episcoporum - spiritual goods - temporary goods.

\section{1) LA CODIFICACIÓN DEL DERECHO CANÓNICO DE $1917^{1}$}

En un trabajo publicado en esta misma revista ${ }^{2}$, en el que analicé las propuestas hechas por los obispos chilenos acerca de la persona jurídica durante el proceso de codificación del derecho canónico iniciado por san Pío X en 1904, hice algunas consideraciones introductorias en torno a dicho proceso codificador, por lo que, con el fin de no repetir conceptos que ya se encuentran publicados en esta misma revista, me permito remitir al lector a dichas páginas en las que encontrará el marco conceptual de este trabajo que ahora presento a su consideración. Me permito, sin embargo, recordar algunas de dichas ideas para que sirvan de introducción a estas páginas.

La tarea de elaborar un "Codex Iuris Canonici" que sustituyera al Corpus fue iniciada por el papa san Pío X (1903-1914) a poco de haber iniciado su pontificado en los albores del siglo XX. Lo hizo mediante el motu proprio "Arduum sane munus", de 19 de marzo de $1904^{3}$, mediante el cual creó una comisión pontificia encargada de asumir la codifica-

1 Abreviaturas: ASV. CIC 1917 = Archivo Secreto Vaticano (Ciudad del Vaticano) Fondo Commissione (Pontificia) per la codificazione del diritto canonico; CIC 1917 = Código de Derecho Canónico de 1917; CIC 1983 = Código de Derecho Canónico de 1983.

2 Salinas Araneda, Carlos (2009). "La persona jurídica en las propuestas de los obispos chilenos a la codificación del derecho canónico de 1917". Revista de Derecho Universidad Católica del Norte, Sección: Estudios, Año 16, Nº 1, pp. 135-166.

3 Publicado en Acta Sanctae Sedis, 1903-1904, vol. 36, pp. 549-551. El motu proprio lleva la fecha 14 de abril de 1904, pero parece que se trata de un error de imprenta, pues en la carta circular "Pergratum mihi", fechada el 25 de marzo de 1904, hay una referencia expresa al motu proprio "Arduum sane munus". Son de esta opinión, LlOBell, Joaquín; De LeÓN, Enrique; Navarrete, Jesús (1999). Il libro "De processibus" nella codificazione del 1917. Studi e documenti. Milano: Giuffrè, vol. I, p. 34 n. 30. Para una historia de la codificación canónica de 1917, por todos puede verse FanTAPpiè, Carlo (2008). Chiesa romana e modernità giuridica, I: L'edificazione del sistema canonistico (1563-1903); II: Il Codex Iuris Canonici (1917). Milano: Per la storia del pensiero giuridico moderno 76, Giuffrè Editore, con bibliografía actualizada. 
ción del derecho de la Iglesia ${ }^{4}$. La elaboración del código, sin embargo, no fue una tarea de un grupo cerrado de iniciados, sino que, contando con el trabajo de un número importante de expertos bajo la dirección de Pedro Gasparri ${ }^{5}$, el mismo motu proprio dispuso la intervención de todo el episcopado latino ${ }^{6}$. De esta manera, una de las principales características del proceso de codificación del derecho canónico de 1917 consistió en la participación, promovida por la misma Santa Sede, del episcopado en la elaboración del Codex. Dicha participación, por cierto, la primera realizada históricamente por la Iglesia al emprender la tarea de elaborar un cuerpo legislativo universal, se articuló en dos grandes momentos: el primero, al inicio de los trabajos de codificación, a través de los "postulata episcoporum"; el segundo, en pleno proceso codificador, cuando se estaba llegando a la fase conclusiva del mismo, a través de las "animadversiones episcoporum". De los dos, el que ahora me interesa es el primero de ellos.

La primera de las consultas fue llevada a la práctica mediante la circular "Pergratum mihi", de la Secretaría de Estado, de fecha 25 de marzo de 1904, enviada a todos los metropolitanos ${ }^{7}$. En ella se disponía que los arzobispos, después de haber oído a sus sufragáneos y otros ordinarios que debían estar presentes en el concilio provincial, debían hacer llegar a la Santa Sede, dentro de los cuatro meses siguientes, en pocas palabras, las principales modificaciones y correcciones que debían hacerse al derecho canónico en vigor ${ }^{8}$.

En la misma circular se comunicaba a los obispos que, por decisión del Santo Padre, los obispos de cada nación tenían la facultad de escoger y enviar a Roma, a su costo, uno o dos especialistas en derecho canónico o teología, que pudiesen formar parte del grupo de consultores; si preferían escoger uno de los que ya habían sido nombrados consultores por los cardenales, podían encargarles que los representara para someter a discusión

La nómina de sus integrantes en Acta Sanctae Sedis, vol. 36, 1903-1904, p. 551.

Antiguo profesor en el Instituto Católico de Paris, entonces arzobispo titular de Cesarea y secretario de la S. Congregación de asuntos eclesiásticos extraordinarios, a quien se le nombró al mismo tiempo presidente de la Comisión de consultores. Posteriormente sería hecho cardenal.

6 En la decisión cuarta el Papa manifestaba su deseo de que todo el episcopado, conformándose a las reglas que serían dadas en tiempo oportuno, colaboraran y concurrieran a esta obra tan importante: "IV. Volumus autem universum episcopatum, iuxta normas opportune tradendas, in gravissimum hoc opus conspirare atque concurrere". La consulta se hizo solo al episcopado latino porque el código estaba previsto solo la para la Iglesia latina.

Actae Sanctae Sedis, vol. 36, 1903-1904, pp. 603-604.

8 Como se ha observado, se solicitó la colaboración del episcopado para que los consultores, con frecuencia hombres más bien teóricos, fuesen iluminados por las condiciones de vida particular en los diferentes países; la consulta era necesaria para asegurar que el nuevo código tuviese un carácter eminentemente práctico y para que, gracias a las sugerencias de los obispos, se eliminasen todas las imperfecciones del derecho vigente, introduciéndole al mismo tiempo las reformas necesarias. Vetulani, A. (1942). "Codex Juris Canonici". En Dictionnaire de Droit Canonique. Paris: vol. III, col. 920. 
y defender sus proposiciones en las reuniones de los consultores; incluso, podían nombrar a alguno de su nación que, residiendo fuera de Roma, pudiese, por correspondencia, aportar de alguna manera a los consultores el apoyo de su colaboración.

La respuesta de los obispos del mundo latino fue amplia, contándose entre ellas la de numerosos obispos latinoamericanos, incluidos los de la provincia eclesiástica del Ecuador. Se calcula en aproximadamente cinco mil el número de personas que fueron consultadas, por lo que, no sin razón, se ha dicho que el trabajo de consulta a los obispos fue como un concilio ecuménico por correspondencia. El numeroso material reunido fue sistematizado en un volumen que permaneció inédito, bajo la dirección del consultor Bernardino Klumper, con el título "Postulata episcoporum in ordine digesta" 9 . Posteriormente se agregó un segundo volumen, más breve que el anterior, con solo 68 páginas, impreso en 1908 con el título "Appendix ad postulata episcoporum", reproducido igualmente por Bernardino Klumper ${ }^{10}$ en el que se recogen, probablemente, las respuestas llegadas con retraso, cuando el primero de estos volúmenes ya estaba en prensa. Ninguno de los dos volúmenes llegó a empastarse y su circulación quedó estrictamente restringida a los consultores, de manera que no fueron conocidos fuera de ellos. Preciso es tener presente, sin embargo, que no todos los "postulata" fueron recogidos por Klumper, por lo que la consulta a los documentos originales se hace indispensable para poder conocer con precisión lo sugerido por los obispos; consulta que es igualmente necesaria cuando se trata de aquellos que fueron incorporados a dicho volumen porque el consultor fue incorporando lo que de ellos consideraba de utilidad o cambió de colocación las sugerencias iniciales ${ }^{11}$.

Como ha sido puesto de relieve ${ }^{12}$, estos "postulata" reflejan el sentir del episcopado mundial en lo que se refiere a la codificación y permiten conocer cuáles eran las preocupaciones y los problemas que interesaban al episcopado mundial a los inicios del siglo XX, no solo de orden jurídico, sino también eclesiológico, disciplinar, pastoral, etc.; desde esta perspectiva, los "postulata" constituyen una útil manera de aproximarse a las realidades de las iglesias locales de la época a partir de unos protagonistas tan directos como son los obispos de cada una de ellas. En ellos se solicitan

9 "Codex Iuris Canonici / Postulata Episcoporum / in ordinem digesta / a / Rmo. P. Bernardino Klumper O. F. M. / Consultore / Romae / Typis Vaticanis / 1905”/, 283 pp. ASV. CIC 1917, caja 4. En adelante: "Postulata".

$10 \quad$ ASV. CIC 1917, caja 6.

11 Al no estar todavía generalizado el uso de la máquina de escribir, la mayoría de los "postulata" son manuscritos, lo que dificulta su lectura, a lo que hay que agregar el que ellos están escritos en diversas lenguas, porque no todos los obispos usaron el latín para sus respuestas, si bien un número importante usó la lengua oficial de la Iglesia.

12 Llobell, Joaquín; De León, Enrique; Navarrete, Jesús (1999) 47-48. 
soluciones que, en no pocos casos, solo fueron adoptadas por el Concilio Vaticano II y el Código de Derecho Canónico de $1983^{13}$.

\section{2) LOS PROTAGONISTAS ECUATORIANOS}

En marzo de 1904, cuando se hace la primera consulta al episcopado, la provincia eclesiástica de Ecuador estaba integrada por el arzobispado de Quito, y los obispados sufragáneos de Cuenca, Guayaquil, Ibarra, Loja, Portoviejo y Riobamba. El arzobispado de Quito estaba vacante por la muerte, el 27 de marzo de 1904, del arzobispo Pedro Rafael González y Calisto, fallecimiento que se producía precisamente en los mismos días en que se enviaba desde Roma la consulta. Obispo de Ibarra era Federico González y Suárez ${ }^{14}$, que había sido electo el 30 de julio de 1895 . Obispo de Riobamba era Arsenio Andrade ${ }^{15}$, preconizado el 13 de noviembre de 1884. Obispo de Guayaquil era Roberto María Pozo y Martín, S.J. ${ }^{16}$, quien había sido nombrado el 13 de noviembre de 1884. Se encontraban vacantes, además del arzobispado, los obispados de Cuenca ${ }^{17}, \operatorname{Loja}^{18}$ y Portoviejo $^{19}$.

El 10 de octubre de 1904, el obispo de Riobamba, Arsenio Andrade, dirigía una $\operatorname{carta}^{20}$ al cardenal Rafael Merry del Val, secretario de Estado

13 Otra circular, esta vez de 6 de abril de 1904, atribuible al secretario de la Comisión, Pedro Gasparri, fue dirigida a los rectores de las universidades católicas para pedirles el concurso "en esta empresa importante y dificil". Circular "Perlegisti", en Acta Sanctae Sedis, vol. 37, 1904-1905, pp. 130-131.

14 Federico González y Suárez nació el 2 de enero de 1845. León XIII (1878-1903) lo nombró obispo de Ibarra el 30 de julio de 1895, siendo consagrado el 8 de diciembre del mismo año, actuando como principal consagrante el arzobispo de Quito, Pedro Rafael González Calixto. Pío X (1903-1914) lo nombró arzobispo de Quito el 14 de diciembre de 1905, tomando posesión de la arquidiócesis el 6 de julio de 1906. Falleció el 5 de diciembre de 1917 cuando el Código de Derecho Canónico estaba ya promulgado, pero aún no entraba en vigencia.

15 Arsenio Andrade Landázuri nació en Uyumbico el 8 de septiembre de 1825. Fue ordenado presbítero en 1855. León XIII (1878-1903) lo nombró obispo de Riobamba (Bolívar) el 13 de noviembre de 1884, siendo consagrado el 25 de enero de 1885, siendo su principal consagrante el arzobispo José Ignacio Ordóñez. Murió en 1907, en pleno proceso de elaboración del Código de Derecho Canónico.

16 Roberto María Pozo y Martín, S.J., nació en Ibarra el 25 de agosto de 1836. León XIII (1878-1903) lo nombró obispo de Guayaquil el 13 de noviembre de 1884. Falleció el año 1909 , cuando ya se había hecho la primera consulta y se trabajaba en Roma en la preparación de los proyectos de código.

17 El obispo anterior, Miguel León Garrido, había fallecido el 31 de marzo de 1900 y su sucesor fue Manuel María Polit, nombrado el 11 de enero de 1907.

18 El obispo anterior, José Massia, O.F.M., había fallecido el año 1902 y su sucesor, Juan Antonio Eguiguren Escudero, fue nombrado el 6 de marzo de 1907.

19 El anterior obispo, Pedro Schumacher, C.M., había muerto el 15 de julio de 1900, y su sucesor, Juan María Riera (Riesa), O.P., fue nombrado recién el 16 de diciembre de 1907.

20 Carta manuscrita en latín, en ASV. CIC 1917, caja 96. 
de Pío X, con la cual le enviaba las proposiciones que los prelados de las diócesis de la provincia eclesiástica del Ecuador habían considerado dignas de someter al estudio y consideración de la comisión romana que tenía la labor de reducir las leyes canónicas a un solo cuerpo. En la misma carta anunciaban que el canónico de la iglesia metropolitana, Manuel María Polit ${ }^{21}$, había sido delegado para presentar también las mismas proposiciones. En carta de este último ${ }^{22}$ a Pedro Gasparri, en su calidad de secretario de la S. Congregación de asuntos eclesiásticos extraordinarios, fechada en Roma el 6 de febrero de 1905, cumplía su encargo y le hacía llegar a la Santa Sede, por su intermedio, el folio de las observaciones de los obispos y otros ordinarios de la provincia eclesiástica de Quito, en la República del Ecuador, acerca de la codificación del derecho canónico, rogándole que le acusara recibo del mismo ${ }^{23}$.

\section{3) LOS “POSTULATA" DE LOS OBISPOS ECUATORIANOS ACERCA DE LOS BIENES ESPIRITUALES}

Los "postulata" de los obispos de la provincia eclesiástica de Quito están contenidos en ocho páginas manuscritas en latín, tamaño folio ${ }^{24}$, en que se formulan sugerencias concretas sobre diversos aspectos del derecho canónico vigente, partiendo por algunas referidas a los principios del

21 Manuel María Polit y Laso nació en Quito el 25 de marzo de 1862. Después de titularse de abogado en Quito y de obtener el doctorado en derecho canónico y civil en la Universidad de Quito, en 1890, inició sus estudios eclesiásticos, siendo enviado a Roma como alumno del Colegio Pío Latinoamericano donde fue ordenado presbítero en diciembre de 1894. Entre 1894 y 1896 residió en el Colegio de San Sulpicio, en París, donde ejerció su ministerio sacerdotal. Regresó a Quito en 1896 donde fue nombrado promotor fiscal de la arquidiócesis, profesor de filosofía racional en el seminario, vicario general y canónigo honorario de la iglesia metropolitana. En 1899 participó en el Concilio Plenario de América Latina en calidad de notario. El 11 de enero de 1907, cuando tenía 44 años, fue nombrado obispo de Cuenca, siendo consagrado en Roma, el 1 de noviembre de 1907, por el cardenal Secretario de Estado, Rafael Merry del Val y Zulueta. El 7 de enero de 1918, a punto de entrar en vigencia el nuevo Código de Derecho Canónico, fue nombrado arzobispo de Quito. Falleció el 30 de octubre de 1932. Carlo Fantappiè dice de él que fue nombrado consultor de la comisión redactora del código en representación del episcopado boliviano. No estoy de acuerdo con esta afirmación, que, me parece, se debe a una lectura incorrecta de la carta que envió a Roma el obispo de Riobamba, adjuntando la respuesta ecuatoriana a la primera consulta. En ella se firma como obispo "bolivariense", nombre latino de la diócesis ecuatoriana de Riobamba. Además, como se puede leer en dicha carta, que adjunto como anexo 1 a este artículo, en ella solo se dice que el canónico hará entrega en Roma de la misma respuesta que se había enviado separadamente desde Ecuador. En ninguna parte se le nombra como consultor. Por lo demás, no he encontrado ninguna participación del episcopado boliviano en la codificación del derecho canónico de 1917. Fantappiè (2008) II, 712, 1205.

22 Carta manuscrita, en ASV. CIC 1917, caja 96.

23 En una nota puesta al margen de la carta se indica que se acusó recibo el 6 de febrero de 1905.

24 ASV. CIC 1917, caja 96. 
derecho, a las que siguen otras sobre las personas, los sacramentos y los bienes temporales. Como no puedo extenderme en el análisis de todas las propuestas que llegaron a Roma desde Ecuador, porque el espacio no me lo permite, abordaré en estas páginas los "postulata" acerca de los bienes espirituales, esto es, los sacramentos y temporales. En otro lugar me he referido a las propuestas que hicieron los prelados ecuatorianos acerca de los principios del derecho y de las personas ${ }^{25}$.

\section{(3.1) COMUNIÓN ANUAL}

La última de las propuestas incluidas en el apartado dedicado a las personas, la número XIV, se refería al precepto de la comunión. Aunque los obispos de la provincia de Quito la incluían entre las propuestas referidas a las personas, me ha parecido mejor incluirla aquí en atención a la materia que trata. Estaba dividida en dos sugerencias diversas; la primera de ellas proponía que todos y cada uno de los fieles de ambos sexos, que hubiesen llegado a los años de la discreción o uso de razón, tuviesen que comulgar cada ańo, de Adviento en Adviento, conforme al precepto de la Santa Madre Iglesia ${ }^{26}$. En la segunda propuesta se hacía presente que la misma Iglesia ordenaba que esta obligación se satisfacía principalmente en el tiempo pascual y en la iglesia parroquial ${ }^{27}$. En realidad, más que sugerencias innovadoras, en ambas se recordaba la disciplina vigente acerca de la comunión, lo que se hacía utilizando casi las mismas palabras con las que el Concilio IV de Letrán (1215) había establecido el precepto de la confesión y la comunión anual, al menos en Pascua ${ }^{28}$. Esta era la disciplina vigente al momento del informe enviado desde Ecuador, pues el canon lateranense había sido confirmado por el Concilio de Trento ${ }^{29}$. Con el nombre de Pascua había que entender el tiempo que iba desde la domínica de las palmas o Domingo de Ramos hasta el domingo "in albis" o de Quasimodo. En América, por breve de Urbano VIII (1623-1644), de

\footnotetext{
25 Salinas Araneda, Carlos, "Los obispos de la provincia eclesiástica de Ecuador y la codificación del derecho canónico de 1917: los "postulata espiscoporum" acerca de ciertos principios del derecho y las personas", en Libro Homenaje al profesor don Alejandro Guzmán Brito (Valparaíso, 2011), en preparación.

26 "XIV a). Omnes et singuli fideles utriusque sexus, quum ad annos discretionis pervenerint, teneatur singulis annis, de Adventu ad Adventum communicare, juxta praeceptum S. Matris Ecclesiae".

27 "XIV b). Eademque Ecclesia hortatur ut huic obligationi potissimum tempore paschali et in ecclesia parochiali satisfiat".

28 Concilio IV de Letrán, can. 21: "Omnis utriusque sexus fidelis, postquam ad annos discretionis pervenerit, omnia sua peccata, semel saltem in anno fideliter confiteatur proprio sacerdoti... suscipiens reverenter, ad minus in Pascha, Eucharistiae sacramentum...". Sobre la historia de este concilio se puede ver García y García, Antonio (2005). Historia del Concilio IV Lateranense de 1215. Salamanca: Centro de Estudios Orientales y Ecuménicos Juan XXIII, 332 pp.

29 Conc. Trid., sess. 13, c. 9 de Eucaristía.
} 
1639, por la escasez de sacerdotes se había permitido a los indios, negros y mestizos cumplir el precepto pascual desde el principio de la Cuaresma hasta la octava de Corpus Christi $i^{30}$. La comunión pascual había que hacerla en la propia parroquia, por lo que no se cumplía el precepto si se hacía en una iglesia distinta, aunque fuese la catedral, a menos que mediase licencia del párroco, del obispo o del vicario general, siendo suficiente la licencia tácita o presunta ${ }^{31}$.

El código, siguiendo de cerca la formulación del lateranense, dispuso en el canon 859 que "todo fiel de uno o de otro sexo, después que haya llegado a la edad de la discreción, esto es al uso de la razón" debía recibir el sacramento de la Eucaristía una vez al año, por lo menos en Pascua, a no ser que, por consejo de su confesor y por alguna causa razonable, juzgase que debía abstenerse por algún tiempo de recibirlo $(\$ 1)$. La comunión pascual debía hacerse desde el Domingo de Ramos hasta la domínica "in albis", si bien los ordinarios locales podían anticipar el tiempo hasta la domínica cuarta de Cuaresma, o prorrogarlo no más allá de la fiesta de la Santísima Trinidad (\$2). Debía aconsejarse que los fieles lo cumplieran en la propia parroquia, si bien podían hacerlo en parroquia ajena, en cuyo caso debían procurar dar cuenta al párroco propio del cumplimiento del precepto $(\$ 3)$. La preocupación de los prelados ecuatorianos de que esta disciplina se conservara en el código, que es como entiendo esta concreta propuesta que en nada innova, quedó ampliamente recogida en el código finalmente aprobado.

\section{(3.2) BENDICIONES}

Una vez terminadas las propuestas referidas a las personas, seguía una serie de nuevas sugerencias sobre materias diversas del tema común de los bienes espirituales, la primera de las cuales sugería una ampliación de sus facultades de bendecir que tenían los párrocos ${ }^{32}$. Según la disciplina vigente, había algunas bendiciones que estaban reservadas exclusivamente al párroco, como la bendición de la fuente bautismal. Había otras que, aun cuando estaban reservadas al párroco, podían ser impartidas por otros sacerdotes por concesión del obispo o por costumbre, como la bendición de las mujeres post partum -que era una especie de purificación- o la aspersión del agua lustral, en los domingos, al pueblo reunido en la iglesia. No estaban reservadas al párroco otras bendiciones como las de las

\footnotetext{
30 De Tobar, Baltasar (1966). Bulario indico. Sevilla: Publicaciones de la Escuela de Estudios Hispano-Americanos de Sevilla 167, vol. II, p. 238 N$^{\circ} 78$.

31 Donoso, Justo (1848-1849). Instituciones de derecho canónico americano. Valparaíso: Imprenta y librería del Mercurio, vol. II, pp. 62-63.

32 "De benedictionibus. I. Ut parochis benedictionum reservationes minuantur, et eorumdem benedicendi facultates amplificentur".
} 
candelas, cenizas, palmas y otras semejantes ${ }^{33}$. Que algunas bendiciones estuvieran reservadas al párroco significaba que solo él podía impartirlas lícitamente.

Los prelados ecuatorianos fueron los únicos en hacer una propuesta tan general en relación con las bendiciones parroquiales ${ }^{34}$; próximos a ellos estuvieron los padres de la provincia de Holanda ${ }^{35}$ y de Burgos (España $)^{36}$, quienes solicitaron que quedara reservada al párroco la bendición de las mujeres post partum. En esta materia, empero, el código no introdujo mayores innovaciones, pues el canon 462 reservó algunas bendiciones solo al párroco, con la consecuencia que solo él podía impartirlas lícitamente, como la bendición nupcial $\left(4^{\circ}\right)$, las casas al tenor de los libros litúrgicos el Sábado Santo u otro día según la costumbre de los lugares $\left(6^{\circ}\right)$, la pila bautismal, bendiciones fuera de la iglesia con pompa y solemnidad $\left(7^{\circ}\right)$. No quedaron reservadas al párroco otras bendiciones que no lo estaban desde antes, como la de las candelas, de la ceniza y de los ramos, de las mujeres después del parto, del fuego, de las semillas, de los huevos u otras del estilo; tampoco, la exposición de las Cuarenta Horas y la bendición subsiguiente, la exposición y bendición de las reliquias y sagradas, imágenes, etc. ${ }^{37}$. La propuesta de Ecuador, en consecuencia, no obtuvo mayor eco en Roma.

\section{(3.3) OFICIO DIVINO}

Seguidamente, los obispos ecuatorianos formulaban dos sugerencias en torno al oficio divino. En la primera, postulaban que la facultad de rezar los maitines y laudes el día anterior entre el meridiano y el ocaso se extendiere al coro catedralicio ${ }^{38}$. En la segunda, pedían que se estableciera que la facultad de rezar maitines y laudes el día anterior pudiera hacerse desde la primera hora postmeridiana, cuando se tratare de oración privada ${ }^{39}$.

"Llámase oficio divino, cierto número, orden y rito de salmos, himnos, lecciones y otras preces que la Iglesia ha instituido y distribuido en horas determinadas para que, en nombre suyo y por los ministros desig-

Donoso (1848-1849) I, p. 248.

Postulata (1905) 82.

Postulata (1905) 79.

Postulata (1905) 85.

Alonso Morán, O.P., Sabino (1963). "Comentario al canon 462”. En Cabreros de Anta, C.M.F., Marcelino; Alonso Lobo, O.P., Arturo; Alonso Morán, Sabino, O.P., Comentarios al Código de Derecho Canónico con el texto legal latino y castellano, I: Cánones 1-681. Madrid: Bac, pp. 734-735.

38 "De officio divino. II a). Ut facultas matutinum cum laudibus pridie recitandi, inter meridien et occasum, etiam cathedralium choris extendatur".

39 "De officio divino. II b). Ut statuatur facultas matutinum cum laudibus pridie recitandi prima hora post meridiem, quum privatum persolvitur". 
nados por ella, se tributen a Dios las debidas alabanzas" ${ }^{\prime 0}$. Dividido en nocturno y diurno, el primero estaba compuesto de los maitines, cantados a la hora de la aurora (= matuta), de los que se separaron después los laudes, llamados así por los salmos "Laudate". Para cumplir con la sustancia del precepto del rezo de las horas canónicas debía observarse el tiempo conveniente a la recitación de cada una de las partes del oficio, esto es, el curso natural de cada hora-veritas horarum-, pero en el caso de maitines y laudes estaba permitido que se dijesen el día precedente transcurrida la mitad del espacio que corría desde el mediodía hasta el ocaso del sol ${ }^{41}$. Se trataba de una concesión otorgada para el rezo privado de las horas, de allí que la primera petición de los obispos ecuatorianos se dirigiese a extenderla también al rezo solemne en los coros catedralicios. Y como el adelanto horario tenía límites, la segunda propuesta iba dirigida a adelantar el horario desde el cual ambas horas podían ser rezadas: desde la primera hora después del mediodía anterior.

El código no dio mayores normas sobre el oficio divino, no obstante que hubo diversos "postulata" referidos a ellos ${ }^{42}$; solo lo hizo para señalar quienes tenían la obligación de rezarlo ${ }^{43}$, por lo que las peticiones de los prelados no tuvieron acogida, no obstante que se incluyeron en la recopilación que hizo Klumper ${ }^{44}$ y algunos episcopados hicieron sugerencias similares ${ }^{45}$.

\section{(3.4) CATECISMO}

Continuaban los prelados ecuatorianos refiriéndose al catecismo, y proponían que, siguiendo las huellas del Concilio Vaticano I (1869-1870) y los votos del mismo, se instituyese un único catecismo de niños para todo el orbe de la tierra ${ }^{46}$. No fueron los únicos obispos en sugerirlo, pues junto a ellos hubo otros seis episcopados que hicieron una propuesta similar, todos los cuales aparecieron citados conjuntamente por Klumper ${ }^{47}$.

Donoso (1848-1849) II, 234

Donoso (1848-1849) II, 238.

Postulata (1905) 30-33. Fueron 23 propuestas, varias de las cuales fueron compartidas por diversos episcopados.

CIC 1917, can. 135, $610 \$ 3,1475$.

Postulata (1905) 32.

Por ejemplo, los padres de la provincia de Burgos (Espańa) pedían que maitines y laudes se pudieren rezar el día anterior; los padres de la provincia de Reims (Francia), Montauban (Francia), el arzobispo de Toulousse (Francia), los obispos chilenos, los de la provincia de Besançon (Francia) y el obispo de Tull (Francia) pedían que ambas horas pudieran rezarse a partir de la segunda hora después de mediodía.

46 "De catechismo. III. Sacri Vaticani Concili vestigia calcando, atque ejusdem vota prosequendo, unicus pro toto terrarum orbe catechismus parvulorum instituatur".

47 El patriarca de Lisboa (Portugal), el obispo de Montauban (Francia), el arzobispo de Toulouse (Francia), el arzobispo de New Orleans (USA), los padres de la provincia de Besançon (Francia) y de la provincia de Tours (Francia), en Postulata (1905) 213. 
Cuatro eran los catecismos en que se había basado el sistema catequético de la Iglesia occidental desde el siglo XVI hasta finales del siglo XIX: i) el de san Pedro Canicio (mediados del siglo XVI), con más de 400 ediciones; ii) el catecismo "Ad parochos" del Concilio de Trento o Catecismo romano, redactado bajo la dirección de san Carlos Borromeo, pero más bien dirigido a servir como guía de los párrocos; iii) el de san Roberto Belarmino, con dos ediciones, una mayor y otra menor, de las que de esta última se hicieron más de 350 ediciones; iv) el de Michele Casati, obispo teatino, publicado en 1765 que sustituyó al de Belarmino. No eran, sin embargo, los únicos, pues ante los mismos cada parroquia se sentía con entera libertad, creándose una situación que modernamente ha sido calificada de desorden y confusión ${ }^{48}$. En esta línea hemos de entender la propuesta de los obispos ecuatorianos.

Pío X no fue ajeno a esta preocupación de la Iglesia, por lo que publicó en 1905 la encíclica "Acerbo nimis" escrita para afirmar la importancia fundamental de la enseñanza de la doctrina cristiana ${ }^{49}$. El mismo año se publicó en Roma un Compendio de la doctrina cristiana prescrito por Su Santidad Pio X a las diócesis de las provincias de Roma, que, reelaborado y después de varias redacciones, fue publicado en 1912 como Catecismo de la doctrina cristiana, si bien fue conocido como el Catecismo de Pio $X^{50}$. Concebido para la diócesis de Roma, fue después recibido en toda Italia, terminando por extenderse por toda la Iglesia, al punto que fue el catecismo "que formó a todas las generaciones de católicos desde principios de siglo hasta el Vaticano II" 51.

El código nada dijo en cuanto a los catecismos, limitándose a una norma genérica según la cual incumbía al ordinario local decretar en su diócesis todo lo concerniente a la instrucción del pueblo en la doctrina cristiana (can. 1336). Con todo, aun cuando la propuesta ecuatoriana no se vio recogida en el código, se vio ampliamente satisfecha con las decisiones que, al margen del código, fue adoptando Pío X, pues la generalización del catecismo elaborado según sus instrucciones hizo que, en la práctica, hubiese un solo catecismo para la enseńanza de los niños.

\footnotetext{
48 ZaGheni, Guido (1998). La edad contemporánea. Curso de historia de la Iglesia. Madrid: San Pablo, vol. IV, pp. 269-270.

49 Pio X Acta, III, pp. 69-84. En castellano en Colección de encíclicas y documentos pontificios (1962). 6a ed. Madrid: Acción Católica Española, Publicaciones de la Junta Nacional, vol. II, pp. 1571-1578.

50 Una edición reciente del mismo, Catecismo mayor de san Pío X. Compendio de la doctrina cristiana (1998). Madrid: Criterio libros, 270 pp.

51 ZaGHeNI (1998) 272.
} 


\section{(3.5) SACRAMENTOS}

Las sugerencias que hacen a continuación los prelados de la provincia de Quito se refieren a dos sacramentos en particular, el orden y el matrimonio. Respecto del primero, la sugerencia es una sola; no sucede así respecto del segundo, respecto del cual formulan siete proposiciones.

\section{(3.5.1) Sacramento del orden}

Sugerían los prelados, que no hubiese intersticios de tiempo para recibir las órdenes menores entre $s^{152}$. En la época en la que hacían esta sugerencia lo obispos ecuatorianos, además de las cuatro órdenes mayores -episcopado, presbiterado, diaconado y subdiaconado- existían cuatro órdenes menores: acolitado ${ }^{53}$, exorcistado ${ }^{54}$, lectorado ${ }^{55}$ y ostia-

52 "De sacramentis. Ordo. V. Nulla sint temporum interstitia pro ordinibus minoribus inter se".

53 Su oficio propio era acompañar y servir al diácono y subdiácono en la misa solemne; encender las luces en la iglesia; llevar los ciriales en los oficios divinos, preparar el agua y el vino. Como intervenía más de cerca en la celebración de los divinos misterios, su orden era el más excelente entre los menores. Donoso (1848-1849) I, 287. "Acerca de los acólitos -escribía san Carlos Borromeo- adviértase que son aquellos que tocan las campanas y que encienden los cirios a la lectura del Evangelio y a la elevación de la sagrada hostia, para demostrarles cuánto deseo deben tener de que todos vengan a la Iglesia a oír la Misa y la prédica y a hacer oración y que para esto tocan las campanas, de tal manera que todo el que pueda participe; y quien no puede venir agradezca a Dios que por esas campanas se le haga saber aquello que se lleva a cabo en la Iglesia de tal manera que él pueda agradecer y pueda rezar por sí mismo y por los otros que van y que no van; y que tengan deseo de que también los infieles y los grandísimos pecadores sean animados por ese sonido y que se conviertan; y además se les diga que no consideren un oficio vil el de tocar las campanas, sino que agradezcan a Dios, que los hace dignos de éste, y conjuntamente siempre que vayan a tocarlas, le pidan que ese sonido sea eficaz para la conversión de las personas y no para su condenación, que haga que las personas sientan compunción por ese sonido y no lo desprecien de ninguna manera". Tratado sobre el orden, el matrimonio y la extremaunción de San Carlos Borromeo (2010). Introducción, traducción y edición bilingüe con notas por Mario Luigi Grignani. Lima: Fondo Editorial Universidad Católica Sedes Sapientiae, p. 129.

54 Su oficio era expeler el demonio de los cuerpos de los bautizados y catecúmenos con la imposición de las manos y exorcismos aprobados por la Iglesia; preparar las cosas necesarias para la bendición del agua lustral; asistir al sacerdote cuando exorciza; acompańar al sacerdote llevando el acetre o caldereta de agua bendita en el asperjes que hace al pueblo. En la época de la codificación, sin embargo, los exorcismos solo los hacía el sacerdote con licencia del obispo, para evitar abusos. Donoso (1848-1849) I, 287-288. Escribía San Carlos Borromeo: "De la santa lectura de las cosas de Dios, es decir de las sagradas y aprobadas por la Iglesia, viene el descubrimiento de espíritus buenos o malos, que son los hombres, por lo que existe el oficio y órdenes de los exorcistas de echar los espíritus malos". Tratado (2010) 125.

55 Su oficio era cantar o recitar clara y distintamente en los divinos oficios las sagradas escrituras de los profetas; antiguamente guardaban también los sagrados códigos y bendecían los nuevos frutos, pero desde hacía tiempo que esas bendiciones estaban reservadas a los sacerdotes. Donoso (1848-1849) I, 288. Escribía san Carlos Borromeo: "A continuación se informe acerca del oficio del lector a aquellos que se ordenan a éste, a fin de que tanto para sí como para los demás lean las cosas de Dios y ha de pensar de ser él solo el lector del pueblo para que no piense en rehuir el esfuerzo, así también a fin de que otros no lean cosa alguna 
rado $^{56}$. Las primeras conferían potestad inmediata en orden a los objetos sagrados pertenecientes al sacrificio, quedando los que las recibían irrevocablemente consagrados al ministerio del altar y obligados a guardar perpetua castidad. Las menores, en cambio, si bien conferían potestad, ella no versaba inmediatamente acerca de los objetos sagrados concernientes al sacrificio, sino sobre otros ministerios inferiores relativos al culto divino ${ }^{57}$.

Para la recepción de las órdenes menores era preciso respetar los intersticios, esto es, el intervalo de tiempo que debía transcurrir desde la recepción de una de las órdenes hasta su promoción a la superior, durante los cuales los ordenados debían ejercitarse en las órdenes recibidas. Tratándose de los intersticios de las órdenes menores, la disciplina vigente a comienzos del siglo XX era la que había fijado el Concilio de Trento $(1545-1563)^{58}$, según el cual la duración de estos plazos se dejaba a disposición del obispo, a quien el mismo concilio daba la facultad de dispensarlos, lo que los dejaba entregados a su entero arbitrio, a diferencia de la dispensa de los intersticios entre las órdenes mayores para la que era menester necesidad o utilidad. Teniendo el obispo tanta libertad para reducir o simplemente obviar los intersticios en cuanto a las órdenes menores, la sugerencia de los prelados ecuatorianos no era muy extraña, aunque fue la única propuesta en este sentido ${ }^{59}$. Bien puede entenderse que lo que deseaban era que la ley general de la Iglesia viniese a sancionar legalmente una situación existente de hecho.

El código reguló el tema sin introducir reformas mayores en la materia abordada por los obispos ecuatorianos, cuya sugerencia no tuvo eco en los nuevos cánones. En efecto, se dejó a la prudencia del obispo el determinar los intersticios entre la primera tonsura ${ }^{60}$ y el ostiariado o entre una y otra de las órdenes menores; pero el acólito no podía ser promovido al subdiaconado sin haberse ejercitado al menos durante un ańo como

no digna de un cristiano y a fin de que no se introduzcan libros o sospechosos o no aprobados en la Iglesia de Dios, y en cambio debe buscar la ocasión donde sea que se halle de leer alguna cosa buena para edificación de las almas y tener estas cosas muy en mente para no ser mudo donde y cuando se necesita hablar de Dios y de sus cosas". Tratado (2010) p. 123.

56 Su oficio era guardar las llaves de la iglesia, abriendo y cerrando sus puertas; custodiar los objetos sagrados contenidos en ella; recibir a los fieles y prohibir la entrada a los infieles y excomulgados. Era el última de las órdenes menores. Donoso (1848-1849) I, 288. Escribía san Carlos Borromeo: "acerca del ostiario que los clérigos han de ser como porteros de toda la Iglesia, de toda la congregación de fieles y abrir y cerrar a quien sea cuando es necesario y tener en cuenta todo. Tratado (2010) 119.

57 Donoso (1848-1849) 287.

58 Conc. Trid., sess. 23, c. 11 de ref.

59 Postulata (1905) 129.

60 "La primera tonsura, que se suele definir praeparatio ad ordines suscipiendos -preparación para recibir las órdenes- no es otra cosa que una ceremonia sagrada por la cual el lego bautizado y confirmado, es agregado al gremio clerical”. Donoso (1848-1849) I, 288. 
acólito (can. $978 \$ 1$ ). En todo caso, nunca podían conferirse, sin licencia especial del Romano Pontífice, las órdenes menores conjuntamente con el subdiaconado, ni conferir la primera tonsura juntamente con alguna de las órdenes menores, ni todas las órdenes menores a la vez $(\$ 2)$.

\section{(3.5.2) Sacramento del matrimonio}

El sacramento del matrimonio fue el tema que acaparó más sugerencias desde Ecuador, un total de siete, la primera de las cuales se refería a los esponsales

i) esponsales: proponían desde Ecuador, por una parte, que los esponsales no tuvieran fuerza en ninguno de los dos foros, ni civil ni canónico, si no estuvieran firmados en instrumento público; y, por otra, que no fueran disueltos por mutuo acuerdo, sino por escritura pública, manteniéndose el impedimento de pública honestidad después de su disolución ${ }^{61}$.

Donoso $^{62}$, después de definir los esponsales con la fórmula latina mutua promissio et aceptatio futurarum nuptiarum (= mutua promesa y aceptación de futuras nupcias), enumeraba los requisitos para la validez canónica de los mismos: i) que la promesa fuese seria y verdadera; ii) que fuese deliberada y exenta de todo miedo grave y error acerca de la persona; iii) que se manifestase con palabras $\mathrm{u}$ otros signos equivalentes; iv) que fuese mutua y aceptada por ambas partes; v) que las personas fuesen hábiles, esto es, que no se hallasen ligados con impedimentos dirimentes ni impedientes, y que tuviesen la edad de siete ańos requerida por el derecho. Cumplidos estos requisitos, los esponsales eran válidos $y$, aunque fueran clandestinos, obligaban en conciencia.

Aun cuando, en lo que ahora me interesa, se exigía que los esponsales se manifestasen con palabras u otros signos equivalentes, no había prescrita canónicamente ninguna formalidad especial. La ley civil, en cambio, heredada de la monarquía española, había establecido la exigencia de la escritura pública. En efecto, la ley española ${ }^{63}$, había dispuesto que "en ningún tribunal eclesiástico ni secular de mis dominios se admitirán demandas de esponsales, sino es que sean celebrados por personas habilitadas para contraer por si mismas según los expresados requisitos y practicados por escritura pública", caso en el que se procedería como si fueran asuntos puramente civiles. El Concilio Plenario de América Latina había abordado el tema expresamente, al punto que les había parecido a los padres

\footnotetext{
61 "Matrimonium. VI a). Sponsalia nullius sint roboris in utroque foro nisi instrumento publico firmata, servata norma a S. Sede (vel ab ordinario) tradenda. Neque dissoluta censeantur, ex mutuo consensu, nisi per scripturam publicam; manente tamen publicae honestatis impedimento post ipsorum dissolutionem".

62 Donoso (1848-1849) II, 150

63 Nueva Recopilación 10, 2, 18 .
} 
conciliares solicitar al papa León XIII la extensión a América Latina de la declaración que, para España, había dado la S. Congregación del concilio el 31 de enero de 1880, según la cual "los esponsales en nuestras provincias, son inválidos, si no se contraen mediante escritura pública, a cuya escritura no pueden suplir las informaciones matrimoniales, ni las diligencias practicadas en la curia diocesana, o en otra parte, con el fin de obtener la dispensa de algún impedimento, aunque de ellas se infiera la promesa formal de contraer matrimonio". Esta petición conciliar había sido benignamente acogida por el Romano Pontífice, quien había concedido la extensión solicitada ${ }^{64}$. Me parece que ha sido esta norma vigente en España, recogida por el Concilio plenario latinoamericano, la que inspiró inmediatamente a los obispos ecuatorianos, aunque, ella venía a materializar una práctica que había estado vigente en América indiana durante largos años y que ahora estaba vigente en el fuero canónico por la extensión hecha por León XIII.

Los obispos ecuatorianos no fueron los únicos en solicitar una formalidad especial para los esponsales ${ }^{65}$, pues a ellos se unieron otros episcopados, aunque sugerían otras formalidades, como que obligaran solo cuando estuvieran por escrito ${ }^{66}$, o que se celebraran ante el párroco y dos testigos $^{67}$, o en otra forma pública determinada ${ }^{68}$. Junto a los obispos ecuatorianos, los obispos chilenos ${ }^{69}$ también postularon la celebración de los esponsales por escritura pública, coincidiendo con otros episcopados, como los obispos de la provincia eclesiástica de Burgos en Espańa, donde la escritura pública era exigencia vigente, e incluso con algunos episcopados donde dicha exigencia, al parecer, no existía como los de Ruan, Lyon y Arras en Francia ${ }^{70}$.

El Código de Derecho Canónico dispuso que la promesa de matrimonio, tanto la unilateral como la bilateral o esponsales, era nula en ambos fueros "si no se hace por medio de escritura firmada por las partes y además por el párroco u ordinario del lugar, o al menos por dos testigos" (can. 1017 $\$ 1)$. Esto es, dispuso una formalidad expresa para la validez de los esponsales, con lo cual se hacía eco de las peticiones hechas en este sentido; pero no llegó a exigir una escritura pública como lo sugerían los obispos ecuatorianos, proposición que, al tener que extenderse la escritura pública ante una autoridad estatal y no eclesiástica, no estaba exenta de un cier-

Concilio Plenario de América Latina, art. 593 n. 1.

Postulata (1905) 141.

Obispos de Cerdeña (Italia), en Postulata (1905) 140.

Arzobispo de Acerenza y Matera (Italia), en Postulata (1905) 140.

Obispos de la región de Benevento (Italia); padres de la provincia de Tours (Francia), en Postulata (1905) 140.

69 Postulata (1905) 142. Salinas Araneda, Carlos (2008). "El primer aporte de los obispos chilenos a la codificación del derecho canónico de 1917: los postulata episcoporum acerca del matrimonio". Historia, vol. 41, julio-diciembre, II, pp. 413-446, esp. 420-423.

70 Postulata (1905) 141. 
to sabor regalista. Por otra parte, la doctrina de la Iglesia como sociedad jurídicamente perfecta sostenida por esos años por el derecho público eclesiástico no favorecía recoger una solución como la postulada por los obispos ecuatorianos ${ }^{71}$.

Los esponsales disueltos daban origen al impedimento de pública honestidad, que impedía el matrimonio entre el ex esposo y la madre, hermana o hija de la ex esposa y viceversa ${ }^{72}$. El código cambió esta disciplina y excluyó del impedimento de pública honestidad los esponsales disueltos, ya se disolvieran por muerte, por mutuo consentimiento o por cualquier otra causa legal. En otras palabras, la petición ecuatoriana de mantenerlo como impedimento después de su disolución no fue acogida.

ii) impedimento de consanguinidad: postulaban los obispos ecuatorianos que el impedimento de consanguinidad dirimiese el matrimonio hasta el segundo grado en la línea colateral; y hasta el tercero y cuarto grado en la misma línea con atingencia al primero o segundo grado ${ }^{73}$.

Al tiempo de la codificación, la consanguinidad en línea recta irritaba el matrimonio en cualquier grado usque in infinitum; lo hacía por derecho natural, según muchos teólogos, en el primer grado; según otros, lo hacía por derecho natural en todos. Lo cierto es que, según Donoso ${ }^{74}$, nunca se había dispensado en esta línea. En línea colateral, en otro tiempo la nulidad alcanzaba hasta el séptimo grado -contado al modo canónico-, limitándose al cuarto grado en el IV Concilio Lateranense (1215), por lo que para las personas que estaban emparentadas en quinto grado o en quinto con cuarto, tercero o segundo, no había impedimento, disciplina que era la vigente al momento de la codificación. La nulidad era por derecho natural solo en el primer grado, según muchos teólogos, aunque había quienes consideraban que el matrimonio en ese grado, si bien sería gravemente ilícito, no sería nulo atendido solo el derecho natural.

El "postulatum" de los obispos ecuatorianos estuvo acompańado del de otros episcopados que abordaron el mismo impedimento: la mayoría estuvo por reducir el impedimento al tercer ${ }^{75}$ y hasta el segundo grado ${ }^{76}$,

71 Fernández Concha, Rafael (1872). Derecho público eclesiástico. Santiago de Chile: Imprenta del Correo, vol. I, 462 pp.; vol. II, 500 pp.

72 Esta disciplina fue fijada por el Concilio de Trento, pues antes los esponsales no cumplidos dirimían el matrimonio hasta el cuarto grado computado al modo canónico. Conc. Trid. sess. 24, c. 3 de ref. matr.

73 "Matrimonium. VI b). Consanguinitas dirimit matrimonium usque ad secundum gradum lineae collateralis; et usque ad tertium et quartum gradum ejusdem lineae cum attingentia ad primum vel secundum gradum".

74 Donoso (1848-1849) II, 158-159.

75 Los padres de las provincia de Rouen (Francia) y de Halifax (Canadá), en Postulata (1905) 167,169 .

76 El vicario capitular de la diócesis de Avezzano (Italia) y otros 19 episcopados, en Postulata (1905) 164. El arzobispo de Alger (Algeria), y otros seis episcopados, en Postulata (1905) 163. Los padres de la provincia de Eger (Hungría) y otros ocho episcopados, en Postulata 
suprimiendo el cuarto grado o dejándolo solo como impedimento impediente ${ }^{77}$. Algunos pedían que se concediese a los obispos facultad para dispensar en algunos grados, sin especificar cuáles ${ }^{78}$, o en tercer grado ${ }^{79}$. Y hubo quien, de conservarse el impedimento hasta el cuarto grado, pedía que se computase conforme a las reglas del derecho civil ${ }^{80}$.

El código conservó el impedimento de consanguinidad en los mismos términos en lo que se refería a la línea recta, pero lo redujo al tercer grado -contado a la manera canónica- en la línea colateral (can. 1076). Se acogía, así, solo en parte la sugerencia ecuatoriana. En todo caso, el impedimento de consanguinidad en tercer grado de la línea colateral -primos en segundo grado- era de grado menor (can. $1042 \$ 2 \mathrm{n}^{\circ} 1$ ), por lo que se dispensaba fácilmente, aunque adoleciese de vicio de obrepción o subrepción (can. 1054). En segundo grado de línea colateral, es decir entre primos hermanos, se dispensaba con facilidad y no estaba reservado a la Santa Sede, como sí lo estaba el impedimento de consanguinidad en segundo grado mezclado con primero, esto es, tíos con sobrinos, para cuya dispensa, además, se requerían causas más graves; también quedaba reservada a la Santa Sede la dispensa de los demás grados. El código de 1983 dio un paso más en lo referido a la dispensa del impedimento existente entre tíos y sobrinos al no dejarlo reservado a la Santa Sede (CIC 1983 , can. $1078 \$ 2$ ).

iii) impedimento de afinidad por cópula lícita: en relación con el impedimento de afinidad, se pedía desde Ecuador que la afinidad proveniente de cópula lícita dirimiese el matrimonio en segundo grado; y en tercero y cuarto con atingencia al primero o al segundo ${ }^{81}$.

Al tiempo de la codificación, la afinidad lícita, esto es, la que se originaba por cópula lícita, dirimía el matrimonio entre el varón y las consanguíneas de la mujer o el de esta con los consanguíneos de aquel hasta el cuarto grado, contado al modo canónico, o sea, hasta los primos en tercer grado. Hasta el IV Concilio Lateranense (1215) se prolongaba hasta el séptimo grado, siendo reducido por dicha asamblea conciliar al cuarto grado, disciplina que, en materia de afinidad lícita, conservó el Concilio de Trento (1545-1563) y era la vigente al momento de la codificación. Disputaban los doctores si la afinidad ex copula conjugali dirimía el matri-

(1905) 168. Otros siete episcopados, en Postulata (1905) 175. El obispo de Apulia (Italia), en Postulata (1905) 177.

77 Los obispos de las diócesis de Arras (Francia) y de San Alberto (Canadá), en Postulata (1905) $170,168$.

78 Los obispos de la región de Calabria (Italia), en Postulata (1905) 170.

79 Los padres de las provincias de Poznan (Polonia), de Salzburgo (Austria) y de Tarragona (España), y los obispos de la región Beneventana (Italia), en Postulata (1905) 176, 178.

$80 \quad$ El obispo de Kandy (India), en Postulata (1905) 174.

81 "Matrimonium. VI c). Affinitas, quae ex copula licita oritur, dirimit matrimonium in secundo gradu aequali; et in tertio et quarto cum attingentia primi vel secundi". 
monio por derecho natural en el primer grado de línea recta, o sea, entre el padrastro y la entenada, o la suegra y el yerno, existiendo numerosos defensores tanto de la respuesta afirmativa como negativa. En la práctica los papas constantemente se habían negado a dispensar en ese grado. En los restantes grados de la línea recta y en los de la línea colateral, se convenía generalmente que el impedimento era de derecho eclesiástico.

En cuanto a la afinidad lícita, la propuesta de los prelados ecuatorianos no fue aislada y estuvo acompañada por otras: el mayor número estuvo por restringirla, no existiendo, empero, unidad de criterio en cuanto a los grados, pues las propuestas iban de restringirlo al tercero ${ }^{82}$, al segundo ${ }^{83} \mathrm{e}$, incluso, al primer grado $^{84}$; o que se diese a los obispos la facultad de dispensar en tercer y cuarto grado ${ }^{85}$, o que simplemente fuese un impedimento impediente.

El impedimento por afinidad fue conservado en el código de 1917, si bien la disciplina antecodicial fue profundamente reformada, porque, a partir del código, la afinidad solo tuvo su origen en el matrimonio válido, estuviese o no consumado y dirimía el matrimonio en cualquier grado de la línea recta y hasta el segundo grado -canónico- en la línea colateral (can. $1077 \$ 1$ ). Se acogía, pues, en los mismos términos la petición ecuatoriana en orden a reducir el impedimento al segundo grado; y se vieron beneficiados con el resto de la propuesta, porque a partir del código desapareció el impedimento en los grados que ellos sugerían. El código canónico de 1983 también dio un paso más en esta materia, al eliminar el impedimento de afinidad en la línea colateral, dejándolo solo reducido a la línea recta (CIC 1983, can. 1092).

iv) impedimento de afinidad por cópula ilícita: en esta materia la petición de los prelados ecuatorianos era muy concreta: que la afinidad originada por cópula ilícita dirimiese el matrimonio solo en el primer grado ${ }^{86}$.

82 Los obispos de Jaffna (Sri Lanka) y los padres de la provincia de Cincinnati (USA), en Postulata (1905) 174; los obispos de la región Beneventana (Italia), en Postulata (1905) 178; los padres de la provincia de Halifax (Canadá), en Postulata (1905) 169; los padres de la provincia de Bombay (India), el obispo de Natchez (USA) y los obispos de Borussia (Alemania), en Postulata (1905) 175. Otros 15 episcopados, en Postulata (1905) 178.

83 Lo solicitaban 28 episcopados, entre los que se encontraban los padres de la provincia de Venezuela, el arzobispo de Guatemala y los obispos de las provincias de Bélgica y de Tokio (Japón), en Postulata (1905) p. 163; el obispo de San Alberto (Canadá), en Postulata (1905) 168; el arzobispo de Kingston (Canadá); el obispo de Clermont (Francia), en Postulata (1905) 168; y otros nueve episcopados, entre los cuales los obispos de Brasilia (Brasil), los de la provincia de Michoacán (México) y los obispos de Irlanda, en Postulata (1905) 175.

84 Diez episcopados entre los cuales los padres de la provincia de Burgos (Espańa), de Montreal (Canadá) y de Escocia, en Postulata (1905) 174; los padres de las provincias de Poznan (Polonia) y de Rouen (Francia), en Postulata (1905) 176; el obispo de Nueva York (USA), los padres de la provincia de Cincinnati (USA) y el obispo de Albano (Italia), en Postulata (1905) 177.

85 El obispo de Apulia (Italia), en Postulata (1905) 177.

86 "Matrimonium. VI d). Affinitas, quae ex copula illicita oritur, dirimit matrimonium in primo gradu tantum". 
La afinidad era definida por Donoso ${ }^{87}$ como "el vínculo o proximidad de las personas, proveniente de acto carnal consumado, lícito o ilícito; la contrae el varón con los consanguíneos de la mujer y ésta con los consanguíneos de aquel". La afinidad ilícita era la que se generaba ex copula fornicaria y, conforme al Concilio de Trento (1545-1563) ${ }^{88}$, dirimía el matrimonio en primer y segundo grado. Los grados de afinidad correspondían a los de consanguinidad y se computaban del mismo modo, por lo que, por ejemplo, Pedro, que había conocido carnalmente a Francisca era afín con la madre e hija de ella, en primer grado de línea recta; con la hermana de la misma, en primer grado de la línea colateral; y con la prima hermana, tía o sobrina, en segundo grado. A veces, la afinidad ex copula ilicita sobrevenía al matrimonio ya contraído, esto es, cuando el trato carnal tenía lugar con los consanguíneos del consorte en primer o segundo grado. En estos casos el matrimonio no se disolvía, pero privaba al delincuente, como se decía en los textos de la época, del derecho a exigir el débito conyugal, de manera que si lo pedía, pecaba gravemente; en cambio no perdía ese derecho el cónyuge que ignoraba el hecho.

El postulatum de los obispos de Ecuador no fue el único en materia de afinidad ilícita. Otros, como ellos, sugirieron restringirlo al primer grado $^{89}$; o restringirlo al primer grado de la línea recta, en tanto que en la otra línea y en los otros grados, derogar el impedimento o simplemente prohibir el matrimonio ${ }^{90}$; o que no dirimiese el matrimonio más allá del primer grado de la línea colateral o derechamente derogarlo ${ }^{91}$; o dejarlo restringido solo a la línea recta ${ }^{92}$. Otros episcopados derechamente pidieron su eliminación ${ }^{93}$. El Código de Derecho Canónico decidió conservar el impedimento dirimente de afinidad, pero, como se ha dicho precedentemente, restringido solo a la afinidad lícita; en otras palabras, el código fue más allá que la petición ecuatoriana, pues acogió las peticiones hechas en orden a eliminar el impedimento en lo referido a la afinidad ilícita.

87 Donoso (1848-1849) II, 164.

88 Conc. Trid. sess. 24 , c. 4 de ref. matrim.

89 Los obispos de las diócesis de Anagni (Italia), de Montauban (Francia), de Concepción de Chile, los obispos de Espańa y de la región de Umbría (Italia), los arzobispos de Bamberg (Alemania) y Guatemala, y los padres de las provincias de Salzburgo (Austria), de Halifax (Canadá), de Lyon (Francia) y de Bourges (Francia), en Postulata (1905) 165.

$90 \quad$ Los padres de las provincias de Paris (Francia) y de Tours (Francia) y el obispo de Würzburg (Alemania), en Postulata (1905) 166.

91 Los padres de las provincias de Rouen (Francia), Brasilia (Brasil), Cincinnati (USA), Lvov (Ucrania), Michoacán (México) y los obispos de Irlanda, en Postulata (1905) 167.

92 Los padres de las provincias de Sydney-Melbourne (Australia) y de Besançon (Francia), en Postulata (1905) 172.

93 Los obispos de las diócesis de Kandy (India), los arzobispos de Alger (Algeria), de Avignon (Francia), de Sardi (Lydia), el patriarca de Lvov (Ucrania), los padres de las provincias de Poznan (Polonia), de Holanda, de Burgos (España), de Aix (Francia), de Eger (Hungría), de Montreal (Canadá), de Sens (Francia), de Albi (Francia), y los obispos de Escocia, de Chile y de la región Subalpina, en Postulata (1905) 163. 
v) impedimento de parentesco espiritual: la propuesta de los prelados de Ecuador era que el impedimento de parentesco espiritual dirimiere el matrimonio solo entre el padrino y el ahijado ${ }^{94}$.

La relación de parentesco espiritual fue más antigua que el impedimento, el que fue introduciéndose, como sucedió con otros impedimentos, por la costumbre y por algunas disposiciones legislativas particulares, hasta que alcanzó carácter universal. De hecho, en las Decretales (1234) se resuelven algunas dudas que suponen la vigencia del impedimento, el que suscitaba problemas por la variedad de situaciones que lo configuraban, agravados por la multiplicidad de padrinos. El Concilio de Trento fijó en dos el número de padrinos y redujo la figura del impedimento a la paternidad espiritual, esto es, entre bautizante y bautizado y entre padrino y bautizado, y a la compaternidad, o sea, entre los padres del bautizado y el bautizante y padrinos ${ }^{95}$.

Donoso $^{96}$ explicaba que se trataba de un impedimento de derecho eclesiástico y, por lo mismo, dispensable, y que dirimía el matrimonio en las siguientes situaciones: i) entre el bautizante y bautizado y padre y madre de este; ii) entre los padrinos y el bautizado, y el padre y madre del mismo; iii) entre el confirmante y el padrino o madrina de confirmación, por una parte, y el confirmado y padre o madre de este por la otra. En el sentir común, este impedimento comprendía también al que, en caso de necesidad, confería el bautismo privado, aceptándose, empero, algunas excepciones ${ }^{97}$.

No fueron solo los prelados ecuatorianos los que realizaron esta sugerencia, pues otro tanto hicieron otros 14 episcopados ${ }^{98}$, en tanto que otros insinuaron derechamente su supresión ${ }^{99}$. Ya en el Concilio Vaticano I (1860-1870) se había indicado modificar este impedimento restringiéndolo al bautizado y padrinos y derogando lo referido al sacramento de la confirmación ${ }^{100}$, por lo que la sugerencia de los obispos ecuatorianos

94 "Matrimonium. VI e). Cognatio spiritualis dirimit matrimonium inter levantem et levatum tantum”.

95 Miguelez Domínguez, Lorenzo (1963). “Comentario al canon 1079”. En Alonso Lobo O.P., Arturo; Miguelez Domínguez, Lorenzo; Alonso Morán, O.P., Sabino, Comentarios al Código de Derecho Canónico. Madrid, Bac, vol. II, pp. 596-597.

96 Donoso (1848-1849) II, 159

97 Donoso (1848-1849) II, 23-24.

98 Los padres de la provincia de Holanda, el obispo de Kandy (India), el arzobispo de Avignon (Francia), los padres de la provincia de Aix (Francia), el obispo de Würzburg (Alemania), el patriarca de Lisboa (Portugal), el obispo de Montauban (Francia), los obispos de Brasilia (Brasil), el obispo de Albano (Italia), los padres de la provincia de Cincinnati (USA), el arzobispo de New York (USA), los obispos de Escocia, los padres de la provincia de Lvov (Ucrania), la provincia de Michoacán (México), en Postulata (1905) 166.

99 El arzobispo de Alger (Algeria) y trece episcopados más, en Postulata (1905) 162.

100 Conte a Coronata, ofm. cap., Matthaeus (1957). Institutiones iuris canonici ad usum utriusque clero et scholarum. De sacramentis tractatus canonicus, III: De matrimonio et de sacramentalibus. 3 ed., Torino: p. 558. 
probablemente tenía su origen en aquella propuesta. Algunos obispos, en cambio, habían sugerido que el parentesco espiritual fuese solo un impedimento impediente ${ }^{101}$; o que simplemente se hiciese una nueva legislación sobre la materia ${ }^{102}$; o que se derogase el proveniente de la confirmación ${ }^{103}$ postulatum que coincidía en parte con quienes sugerían que se produjese solo por el bautismo solemne y entre el bautizado y los padrinos ${ }^{104}$.

El Código de Derecho Canónico no eliminó el impedimento, pero, recogiendo lo que ya se había sugerido en el Concilio Vaticano I, lo limitó al establecer que "solamente el bautizante y el padrino contraen por el bautismo parentesco espiritual con el bautizado" (can. 768, 1079). Se trataba, además, de un impedimento de grado menor (can. $1042 \$ 2 \mathrm{n}^{\circ} 4$ ), por lo que la dispensa del mismo se concedía con facilidad ${ }^{105}$. De esta manera, la propuesta ecuatoriana tuvo pleno eco en el código finalmente promulgado.

vi) impedimento de crimen: la siguiente sugerencia de los prelados ecuatorianos se refería al impedimento de crimen, y en ella solicitaban que se suprimiese el impedimento de crimen por adulterio, salvo el conyugicidio o las maquinaciones para el conyugicidio. "Con el nombre de crimen se designa el impedimento dirimente que nace, o del adulterio solo, o del conyugicidio, o del adulterio unido al conyugicidio"106. Para que el adulterio configurara este impedimento se requerían diversas condiciones: i) que fuese verdadero y formal de una y otra parte, por lo cual no había impedimento si, por ejemplo, una de las partes ignoraba que la otra era casada; ii) que fuese consumado, es decir, que hubiese intervenido copula perfecta ad generationem apta; iii) que antes o después interviniese promesa de matrimonio aceptada por la otra parte; y iv) que la promesa y el adulterio se verificaran durante la vida del cónyuge. Por su parte, el conyugicidio sin adulterio constituía impedimento cuando: i) había mutua maquinación o conspiración, por lo que no era suficiente dar muerte al cónyuge si la otra parte ignoraba la acción; ii) que se siga la muerte del cónyuge; iii) que la muerte se haya maquinado con la expresa intención de contraer matrimonio por, al menos, uno de los cónyuges. El conyugicidio con adulterio no requería conspiración o maquinación

101 El obispo de San Alberto (Canadá), el obispo de Londres (Canadá), el obispo de Newark (USA), en Postulata (1905) 168.

102 El arzobispo de Baltimore (USA) y el obispo de Ogdensburg (USA), en Postulata (1905) 169.

103 Los obispos de Cincinnati (USA), los padres de la provincia de Halifax (Canadá) y el obispo de Irenton, en Postulata (1905) 169.

104 Los padres de la provincia de Tarragona (España), en Postulata (1905) 170.

105 De Salazar Abrisquieta, José (1977). "Capacidad e impedimentos matrimoniales". En Catedráticos de derecho canónico de universidades españolas, Derecho canónico. Reimp. 2a ed. Pamplona: Eunsa, p. 428.

106 Donoso (1848-1849) II, 159. 
previa, ni tampoco que hubiese promesa de matrimonio, pero se requería que la muerte se ejecutara con la intención de contraer matrimonio, aunque la intención no fuera conocida por la otra parte ${ }^{107}$.

No fue la única propuesta en este sentido, pues a la de los prelados ecuatorianos se unió, en el mismo sentido, la de otros 14 episcopados ${ }^{108}$. Sin embargo, el Código de Derecho Canónico no recogió esta sugerencia porque, entre las figuras comprendidas en el impedimento de crimen, dispuso que no podían contraer matrimonio válidamente "los que durante un mismo matrimonio legítimo cometieron entre si adulterio consumado y se dieron mutuamente palabra de matrimonio o atentaron éste, aunque solo sea civil" (can. $1075 \mathrm{n}^{\circ} 1$ ).

vii) revalidación del matrimonio por impedimento oculto: sugerían desde Ecuador que se pudiesen revalidar los matrimonios nulos por impedimentos ocultos sin renovación del consentimiento ni conocimiento a la otra parte ignorante de la nulidad ${ }^{109}$. Impedimento oculto era aquel que no podía probarse en el fuero externo ex natura sua, ni tenían noticia de él, al menos cinco o seis personas ${ }^{110}$. Si de dicho impedimento tenían conocimiento las dos partes, ambas debían renovar el consentimiento. Si solo una parte lo conocía, debía revelarse a la parte ignorante la nulidad del primer consentimiento, pero sin descubrirle la causa o delito de donde había provenido y ambas debían renovar entre sí el consentimiento. El problema se presentaba cuando la revelación de la nulidad podía producir males graves como que la otra parte no quisiese renovar el consentimiento y que los hijos quedaran abandonados y sin medios de subsistencia, casos para los cuales los teólogos sugerían algunos medios indirectos para obtener la renovación del consentimiento de parte del cónyuge que ignoraba el impedimento sin que fuese necesario revelarle la nulidad del primero ${ }^{111}$. Era el riesgo de estos inconvenientes el que movía a los prelados ecuatorianos a esta sugerencia, la única hecha en estos términos ${ }^{112}$.

El código se hizo eco de esta propuesta, pues dispuso que en aquellos casos en que se trataba de impedimento oculto y desconocido por una de

107 Donoso (1848-1849), II, 159-160.

108 El obispo de Anagni (Italia), los padres de la provincia de Paris (Francia), los obispos de Espańa, el obispo de Kandy (India), los padres de la provincia de Burgos (España), la provincia de Aix (Francia), la provincia de Eger (Hungía), el patriarca de Lisboa (Portugal), los padres de la provincia de Montreal (Canadá), la provincia de Sens (Francia), la provincia de Lyon (Francia), los obispos de Escocia, el obispo de Kumbakonan (India), los padres de la provincia de Pondicherry (India), en Postulata (1905) 164-165.

109 "Matrimonium. VI g). Ut matrimonium nulla ob oculta impedimenta sine consensus renovatione, nec alterius partis nullitatem ignorantis cognitione revalidari valeant".

110 Donoso (1848-1849) II, 189.

111 Las expone Donoso, Justo (1862). Manual del párroco americano. 2a ed. Valparaíso: pp. 353-354.

112 Postulata (1905) 193. 
las partes, bastaba que solo la parte que lo conocía renovase el consentimiento en forma privada y en secreto, con tal que perseverase el consentimiento prestado por la otra parte (can. $1135 \$ 3$ ). De esta manera, la propuesta llegada a Roma desde Ecuador tuvo pleno eco en el código promulgado.

\section{4) LOS “POSTULATA" DE LOS OBISPOS ECUATORIANOS ACERCA DE LOS BIENES TEMPORALES}

\section{(4.1) BENEFICIOS}

Era la penúltima de las sugerencias provenientes de Ecuador, en la que se pedía que se conservase la ley del concurso en su rigor original, con las especificaciones que la misma propuesta agregaba ${ }^{113}$. Con el nombre "beneficio" se designó originalmente el predio fiscal que los emperadores romanos solían dar a los jefes y soldados beneméritos que se distinguían en la defensa de Roma, para que así pudieran proporcionarse, en su retiro y en la ancianidad, una conveniente subsistencia. La Iglesia siguió este ejemplo y empezó a distribuir predios a los clérigos beneméritos para que se alimentasen con sus productos; estos predios se llamaron "beneficios" y el clérigo que los obtenía, "beneficiado". En un comienzo estas concesiones fueron raras $y$, ordinariamente, se concedían por un tiempo, transcurrido el cual volvían a la Iglesia. Con el tiempo, especialmente cuando se extinguió la vida común de los clérigos, se transformó en la manera ordinaria para asegurar su subsistencia. Donoso ${ }^{114}$ lo definía como "derecho perpetuo, instituido por autoridad de la Iglesia, que compete al clérigo, por razón de un oficio espiritual, para percibir, en nombre propio, cierta parte de los frutos de los bienes eclesiásticos". La importancia de este instituto para la vida de la Iglesia no era menor, por lo que las normas se fueron sucediendo en el tiempo, configurando una compleja regulación ${ }^{115}$.

El código le dedicó casi un centenar de cánones (can. 1409-1488), como no podía ser menos, pues el sistema beneficial había sido el núcleo fundamental del derecho patrimonial eclesiástico desde la Edad Media y seguía siéndolo a comienzos del siglo XX. Pero el desarrollo de la economía mobiliaria y, particularmente, la ruina del patrimonio territorial de la Iglesia a consecuencia de las desamortizaciones del siglo XIX, exigió de

\footnotetext{
113 "De beneficiis. VII. Strictim lex de concursu in suo primaevo rigore maneat, cum omnibus regulis, adjunctis et praevisionibus quae idem jus, sive ad incommoda praecavenda, sive ad privationem, resignationem permutationemque spectantia, easque regulantia habet et jubet".

114 Donoso (1848-1849) II, 290.

115 Donoso (1848-1849) II, 290-321.
} 
la Iglesia un "verdadero alarde de imaginación”, que plasmó en el código. El siglo XX fue, sin embargo, el marco cronológico de la crisis del sistema beneficial ${ }^{116}$. La sugerencia de los prelados ecuatorianos fue incorporada en la síntesis que hizo Klumper de los "postulata"117, por lo que fue conocida por los codificadores; fue, en todo caso, una propuesta más bien genérica que tuvo que ser adecuada a las nuevas realidades que vivía la Iglesia.

\section{(4.2) BIENES ECLESIÁSTICOS}

La última de las propuestas llegadas a Roma desde Ecuador se refería a los bienes eclesiásticos, en concreto, a la administración de los bienes de congregaciones de votos simples y de misioneros; pedían que en la ley canónica se estableciera el modo en que el obispo y el moderador de la congregación debía asignar las donaciones, ya a la congregación ya a la obra pía, cuando el donante nada había indicado con palabras cla$\operatorname{ras}^{118}$.

Convenían los canonistas en que si constaba suficientemente la voluntad de los oferentes, se debía satisfacer esa intención y aplicar conforme a ella las oblaciones, pues siendo estas voluntarias, el donante era árbitro para destinarla al objeto que le agradase. También convenían en que si había costumbre que definiera el destino de esos bienes, había que estarse a ella. La duda se presentaba cuando ni era clara la voluntad del donante ni había costumbre al efecto ${ }^{119}$, que es lo que pedían los prelados ecuatorianos que se aclarase ${ }^{120}$. El código reconoció el derecho de los fieles para dejar bienes para causas piadosas, ya por acto entre vivos, ya por acto por causa de muerte (can. $1513 \$ 1$ ); y dispuso que los ordinarios eran ejecutores de todas las piadosas voluntades, tanto por causa de muerte como entre vivos (can, $1515 \$ 1$ ), salvo que el donante o testador hubiese designado ejecutores. Pero no estableció las reglas que se pedían desde Ecuador.

116 Mostaza Rodríguez, Antonio (1977). “Derecho patrimonial canónico”. En Catedráticos de derecho canónico de universidades españolas, Derecho canónico. Reimp. $2^{a}$ ed. Pamplona: Eunsa, pp. 329-331.

117 Postulata (1905) 224. Hubo 26 sugerencias en lo referido a la colación del beneficio, lo que muestra el interés de la materia. De ellas, 11 se referían a los concursos.

118 "De bonis ecclesiae. VIII. Ut in lege canonica de bonorum administrations congregationum votorum simplicium et missionariorum statuatur quomodo se gerere debeant episcopus et moderator congregationis in asssignandis donis, sive congregrationis sive pio opera, quum donator nihil verbis perspicuis indicaverit".

119 Donoso (1848-1849) II, 324-325.

120 Postulata (1905), 242. Fue la única propuesta en materia de donaciones y otros contratos en particular: Caput V. De donationibus aliisque contractibus in specie". 


\section{CONCLUSIONES}

Llegados al final de estas líneas en las que he hecho un primer análisis de la participación de los obispos de la provincia eclesiástica de Quito en el proceso de codificación del derecho canónico emprendido por san Pío X al inicio del siglo XX, podemos hacer la siguiente valoración general:

1. Los obispos de la provincia eclesiástica de Quito, al igual que el resto del episcopado latinoamericano, fueron consultados durante el proceso de codificación del derecho canónico de 1917, siguiendo el deseo de san Pío X que quería ver involucrado en ese proceso a todo el episcopado. Dicha consulta se articuló en dos momentos, al inicio de los trabajos, a efectos de que sugirieran las principales modificaciones y correcciones al derecho vigente $y$, una vez que estuvieron redactados los proyectos parciales de los diversos libros que lo compondrían, para que formularan sus observaciones.

2. El numeroso material reunido con las respuestas de los obispos a la primera de las consultas fue sistematizado en un volumen que permaneció inédito, bajo la dirección del consultor Bernardino Klumper, con el título "Postulata episcoporum in ordine digesta". En él se incluyeron, debidamente sistematizadas, las respuestas de los diversos episcopados del mundo, y también las de los obispos de Ecuador

3. En cuanto a las propuestas analizadas en estas páginas, es decir aquellas hechas en respuesta a la primera consulta y referidas a los bienes espirituales y temporales, constituyen ellas una expresión parcial, pero muy real, de aspectos de la realidad eclesial de la provincia eclesiástica de Quito, particularmente en lo que los obispos consideraban los problemas más acuciantes que debían enfrentar a la luz del derecho canónico, los que, a la luz de estas propuestas, se sitúan más bien a nivel intraeclesial, como lo muestra la simple lectura de los mismos.

4. La mayoría de las propuestas del episcopado ecuatoriano arrancan de la experiencia pastoral de los prelados, por lo que no es de extrańar que un número importante de sus sugerencias se refiera al matrimonio, una de las realidades más cotidianas con la que tenían que enfrentarse en su gobierno pastoral.

5. No hay constancia de que en la elaboración de estas propuestas hubiesen participado algunas personas diversas a los obispos que por entonces estaban al frente de sus diócesis en Ecuador, pero hay algunas propuestas que permiten advertir la participación de algunas personas, en concreto, algunos miembros del cabildo eclesiástico de Quito, pues no solo hay algunas sugerencias especiales referidas a ellos, sino que todas ellas buscan mejorar su situación. Un ejemplo de ello se encuentra en una de las propuestas analizadas en estas páginas, que versa sobre el oficio divino, la que buscaba extender al 
rezo del mismo hecho en el coro por los canónigos, y, por lo mismo, oración oficial de la Iglesia, lo que ya estaba autorizado para el rezo privado del oficio en cuanto a poder adelantar el horario del mismo.

6. Algunas de las sugerencias de los prelados ecuatorianos no fueron aisladas, sino que fueron compartidas por otros episcopados, lo que es expresión, por una parte, de la relevancia de los problemas observados, lo que lleva a varios episcopados a preocuparse de ellos. Pero es también expresión de la sintonía de los prelados de Ecuador con otros episcopados del mundo, que les lleva a sentir, al igual que ellos, los mismos problemas eclesiales.

7. Otras sugerencias que arribaron desde Quito a Roma fueron originales de los prelados ecuatorianos, expresión, como ya lo he advertido, de los problemas peculiares que advertían en sus iglesias. Algunas de estas sugerencias tuvieron eco en el código finalmente promulgado; otras no fueron consideradas, pues la solución por la que finalmente optó el codificador fue diversa a la sugerida por los prelados latinoamericanos.

8. Llama la atención la escasa relevancia que le dan los prelados ecuatorianos a los bienes temporales de la Iglesia, pues solo dos de las propuestas se refirieron a ellos, y una de ellas, incluso, trata de la administración de bienes en congregaciones religiosas. Estas escasas propuestas pueden ser expresión que no había mayores dificultades en esta materia.

9. Ninguno de los prelados que intervinieron en estas propuestas, con excepción del canónigo Polit, participó en el Concilio Plenario de América Latina celebrado en Roma en 1899 y no hay en sus sugerencias ninguna referencia al mismo, no obstante que cuando las enviaron a Roma ya estaban publicadas, en un primer volumen, las actas del mismo y en un segundo volumen los anexos. Esto es así, a diferencia de lo sucedido con otros "postulata" de obispos latinoamericanos que participaron en dicho concilio, en los que hacen referencias expresas al mismo.

\section{BiBLIOGRAFÍA}

Alonso Lobo O.P., Arturo; Miguelez Domínguez, Lorenzo; Alonso Morán, O.P., Sabino, Comentarios al Código de Derecho Canónico. Madrid: Bac, vol. II, 912 pp.

Cabreros de Anta, C.M.F., Marcelino; Alonso Lobo, O.P., Arturo; Alonso Morán, Sabino, O.P. (1963). Comentarios al Código de Derecho Canónico con el texto legal latino y castellano. Madrid: Bac, vol. I, 963 pp. 
Catecismo mayor de san Pio X. Compendio de la doctrina cristiana (1998). Madrid: Criterio libros, 270 pp.

Colección de encíclicas y documentos pontificios (1962). 6a ed. Madrid: Acción Católica Española, Publicaciones de la Junta Nacional, vol. II, pp. 1571-1578.

Conte a Coronata, ofm. cap., Matthaeus (1957). Institutiones iuris canonici ad usum utriusque clero et scholarum. De sacramentis tractatus canonicus, III: De matrimonio et de sacramentalibus. 3 ed., Torino: 452 pp.

De Salazar Abrisquieta, José (1977). "Capacidad e impedimentos matrimoniales". En Catedráticos de derecho canónico de universidades españolas, Derecho canónico. Reimp. 2a ed. Pamplona: Eunsa, pp. 399-430.

De Tobar, Baltasar (1966). Bulario indico. Sevilla: Publicaciones de la Escuela de Estudios Hispano-Americanos de Sevilla 167, vol. II, 435 pp.

Donoso, Justo (1848-1849). Instituciones de derecho canónico americano. Valparaíso: Imprenta y librería del Mercurio, vol. I, 316 pp.; vol. II, 478 pp.

$$
\text { pp. }
$$

(1862). Manual del párroco americano. 2a ed. Valparaíso: 490

Klumper, Bernardino (1905). Codex Iuris Canonici. Postulata Episcoporum in ordinem digesta a Rmo. P. Bernardino Klumper $O$. F. M. Consultore. Romae: Typis Vaticanis, 283 pp. Archivo Secreto Vaticano (Ciudad del Vaticano) Fondo Commissione (Pontificia) per la codificazione del diritto canonico, caja 4. Se cita como Postulata.

Fantappiè, Carlo (2008). Chiesa romana e modernità giuridica, I: L'edificazione del sistema canonistico (1563-1903); II: Il Codex Iuris Canonici (1917). Milano: Per la storia del pensiero giuridico moderno 76, Giuffrè Editore, $1282 \mathrm{pp}$.

Fernández Concha, Rafael (1872). Derecho público eclesiástico. Santiago de Chile: Imprenta del Correo, vol. I, 462 pp.; vol. II, 500 pp.

García y García, Antonio (2005). Historia del Concilio IV Lateranense de 1215. Salamanca: Centro de Estudios Orientales y Ecuménicos Juan XXIII, $332 \mathrm{pp}$.

Grignani, Mario (2010). Tratado sobre el orden, el matrimonio y la extrema unción de San Carlos Borromeo. Introducción, traducción y edición bilingüe. Lima: Fondo Editorial Universidad Católica Sedes Sapientiae, $175 \mathrm{pp}$.

Llobell, Joaquín; De León, Enrique; Navarrete, Jesús (1999). Il libro "De processibus" nella codificazione del 1917. Studi e documenti. Milano: Giuffré, vol. I, 1303 pp.

Mostaza Rodríguez, Antonio (1977). "Derecho patrimonial canónico". En Catedráticos de derecho canónico de universidades españolas, Derecho canónico. Reimp. 2a ed. Pamplona: Eunsa, pp. 315-377. 
Salinas Araneda, Carlos (2008). "El primer aporte de los obispos chilenos a la codificación del derecho canónico de 1917: los postulata episcoporum acerca del matrimonio". Historia, vol. 41, julio-diciembre, II, pp. 413-446.

(2009). "La persona jurídica en las propuestas de los obispos chilenos a la codificación del derecho canónico de 1917". Revista de Derecho Universidad Católica del Norte, Sección: Estudios, Año 16, $\mathrm{N}^{\circ} 1$, pp. 135-166.

Vetulani, A. (1942). "Codex Juris Canonici”. En Dictionnaire de Droit Canonique. Paris: vol. III, col. 920-933.

Zagheni, Guido (1998). La edad contemporánea. Curso de historia de la Iglesia. Madrid: San Pablo, vol. IV, pp. 269-270. 